\title{
The Bacillus subtilis genes for ribonucleotide reductase are similar to the genes for the second class I NrdE/NrdF enzymes of Enterobacteriaceae
}

\author{
Claudio Scotti, ${ }^{1}+$ Angela Valbuzzi, ${ }^{1}$ Marta Perego, ${ }^{1,2} \ddagger$ Alessandro Galizzi ${ }^{1}$ \\ and Alessandra M. Albertini ${ }^{1}$
}

Author for correspondence: Alessandra M. Albertini. Tel: +39 382 505549. Fax : + 39382528496. e-mail: Albert@pillo.unipv.it

1 Dipartimento di Genetica e Microbiologia, 'A. Buzzati Traverso' Università degli Studi di Pavia, Italy

2 Dipartimento Farmaceutico, Università degli Studi di Parma, Parma, Italy

\begin{abstract}
We have cloned and sequenced the nrd (nucleotide reductase) locus of Bacillus subtilis. The locus seems to be organized in an operon comprising four ORFs. The first three encode polypeptides highly similar to the product of the coding sequences characterizing the nrdEF operons of Enterobacteriaceae. The sequencing of the conditional lethal mutation ts-A13, localized in the nrdE cistron, and the lethality of insertional mutations targeted in the internal region of nrdE and nrdF, demonstrated the essential role of this locus. The fourth ORF, ymaB, part of the putative operon, which is not similar to any known protein, is also essential. The regulation of expression of the operon, monitored by lacz transcriptional fusions, is similar to the regulation of the functionally relevant nrdAB operon of Escherichia coli. The operon was induced by thymidine starvation and its expression was directly or indirectly affected by RecA function. Genetic and functional analysis strongly indicates that in $B$. subtilis the class I ribonucleotide reductase encoded by this nrd operon is evolutionarily distant from the homologous class I enzyme of Enterobacteria.
\end{abstract}

Keywords: Bacillus subtilis, genome sequencing, ribonucleotide reductase, $n r d E F$ operon, ts- $A 13$ mutation

\section{INTRODUCTION}

Ribonucleotide reductases (RRs, ribonucleoside diphosphate reductases) are enzymes essential for the biosynthesis of deoxyribonucleotides from the corresponding ribonucleotides. In addition they exert an important role in balancing the supply of the four dNTPs and consequently in the control of DNA synthesis. In prokaryotes the presence of three classes of enzymes has been documented (Reichard, 1993). Class I enzymes, the best known from structural studies (Nordlund et al., 1990; Nordlund \& Eklund, 1993; Uhlin \& Eklund, 1994), are tetrameric, aerobic and use, for the generation of the

† Present address: IGBM, 19 rue C. Roux, CH 1005 Lausanne, Switzerland. ¥ Present address: The Scripps Research Institute, Division of Cell Biology, La Jolla, CA 92037, USA.

Abbreviations: nrd, Nrd, nucleotide reductase; RR, ribonucleoside diphosphate reductase; $\mathrm{Ap}$, ampicillin; $\mathrm{Cm}$, chloramphenicol; $\mathrm{Km}$, kanamycin; TC, tetracycline.

The GenBank accession number for the sequence reported in this paper is 268500 . organic radical necessary in the initial step of the enzymic reaction, an iron-containing protein, represented by the $\mathbf{R}_{2}$ homodimer. The $\mathbf{R}_{1}$ homodimer contains the allosteric binding sites and the catalytic site. Class II enzymes, present in different aerobic and anaerobic prokaryotes, are monomeric and use adenosyl cobalamin as radical generator (Booker \& Stubbe, 1993) taking over the function of the $R_{2}$ protein of the class I enzymes. The amino acid sequence has no similarity with $R_{1}$ with the exception of nine amino acids at the $\mathrm{C}$ terminus. The class III enzyme was discovered in Escherichia coli growing anaerobically. It is a homodimer with an iron-sulfur centre and an oxygensensitive protein radical probably represented by a Gly radical close to the $C$ terminus (Sun et al., 1993). A similar function is encoded by bacteriophage T4. Comparison of the amino acid sequences of class I enzymes of different species suggested the existence of three different groups, namely eukaryotic $R R$, herpesvirus-type enzymes, and $E$. coli and bacteriophage T4 $n r d A B$ gene products (Nordlund \& Eklund, 1993), with a very low level of similarity between them (at the boundary of significance, between 20 and $30 \%$ identity). Recently, the genes encoding a 
fourth group of class I enzymes were identified in Salmonella typhimurium and E. coli and named nrdEF (Jordan et al., 1994a). This new operon, when carried on a multicopy plasmid, can complement $n r d A B$ conditional lethal mutants in standard growth conditions, suggesting that it encodes an aerobic function, usually expressed at low level. The deduced products of $n r d E F$ showed only limited homology with the other groups of class I enzymes (between 19 and $27 \%$ identity) but many of the catalytically important amino acid residues were conserved. The products of the two genes, $n r d E$ and $n r d F$, are homodimeric proteins: the $\mathrm{R} 1_{\mathrm{E}} \mathrm{R} 2_{\mathrm{F}}$ enzyme is able to catalyse the reduction of CDP to dCDP in the presence of dithiothreitol or reduced glutaredoxin as an electron donor, instead of thioredoxin, and its allosteric regulation is different from that exhibited by the enzyme encoded by the $n r d A B$ operon (Jordan et al., 1994b).

In $E$. coli the expression of the $\operatorname{rrd} A B$ operon is cell-cycleregulated (Filpula \& Fuchs, 1977, 1978; Sun \& Fuchs, 1992) with a cis-acting positive A-T-rich element (Sun $e t$ al., 1994) as regulator. Two trans-acting positive regulators are DnaA and Fis (Augustin et al., 1994), but these proteins are not required for the coupling of $\operatorname{nrd} A B$ operon expression to DNA synthesis during the cell cycle. The activity of $R R$ and the transcription of the operon are both increased when DNA replication is inhibited (Hanke \& Fuchs, 1983) and after DNA damage (Gibert et al., 1990 ), but this increase seems to be only indirectly related to DNA damage.

In Bacillus subtilis the isolation and characterization of a temperature-sensitive mutant ( $t s-A 13)$ led to the identification of the $n r d$ locus encoding a RR, functionally similar to the aerobic class I RR of E. coli (Bazill \& Karamata, 1972). In a marker rescue screening, a clone positive for the $t s-A 13$ allele (previously named $d n a A-13$ ) was isolated from a plasmid bank of $B$. subtilis genomic DNA (Perego et al., 1987). The $n r d(d n a A)$ locus was mapped at about $167^{\circ}$ on the chromosome, between the $g \ln \mathrm{R} A$ operon and the ples locus (Fisher et al., 1984; Giannì \& Galizzi, 1986; Scotti et al., 1993). In this paper we describe the molecular cloning and sequencing of the entire $B$. subtilis nrd locus, the localization and nature of the $t s-A 13$ mutation, gene inactivation experiments and preliminary results on the regulation of expression of the locus.

\section{METHODS}

Bacterial strains, plasmids and media. $B$. subtilis strains used for gene inactivation and transcriptional fusion are listed in Table 1. E. coli DP50 (supF $\left[\mathrm{F}^{-}\right.$ton $A 53$ glnV-44 tyrT-58 dapD8 lac $Y-1$ supE-44 supF-58 $\Delta$ (gal-uvrB) 47 gyr $A-29$ tby $A-57$ bsd $S$-3]) and LE392 (supE-44 supF-58 bsdR-514 galK-2 galT-22 metB-1 $\operatorname{trpR}-55$ lac $Y-1$ ) were used as hosts for $\lambda$ Charon $4 \mathrm{~A}$ recombinant derivatives. Cultures were grown in TY medium (tryptoneyeast extract medium supplemented with $100 \mu \mathrm{g}$ diaminopimelic acid $\mathrm{ml}^{-1}$ and $50 \mu \mathrm{g}$ thymidine $\mathrm{ml}^{-1}$ in the case of strain DP50) or LB medium.

Antibiotics were added at the following concentrations: ampicillin (Ap), $100 \mu \mathrm{g} \mathrm{ml}^{-1}$; chloramphenicol (Cm), $20 \mu \mathrm{g} \mathrm{m}^{-1}$ for $E$. coli and 2.5 or $5 \mu \mathrm{g} \mathrm{ml}{ }^{-1}$ for $B$. subtilis, kanamycin $(\mathrm{Km}), 2 \mu \mathrm{g}$ $\mathrm{ml}^{-1}$. E. coli DH5 $\alpha$ [supE44 lacU169 ( $\phi 80$ lacZ $\left.\Delta \mathrm{M} 15\right)$ bsdR 17 $\operatorname{rec} A 1$ end $A 1 \operatorname{gyr} A 96$ thi-1 relA1] was used for plasmid transformation and propagation. The genomic $B$. subtilis $\lambda$ Charon 4A bank was made with DNA from strain 168 (trpC-2) (Ferrari et al., 1983). The insert from the $2 \mathrm{CH} 4 \mathrm{G} 621$ clone was sub-cloned in the pJM103 integrative vector (Perego, 1993); the integrative vectors $\mathrm{pJM} 783$ and $\mathrm{pJM} 115$ were used to generate transcriptional fusions to lac $Z$ (Perego, 1993).

Two transcriptional fusions were constructed, one placing the reporter gene, lac $Z$, downstream of the whole operon to evaluate the expression of the operon. The second fusion was constructed to test the presence of a putative promoter between $n r d F$ and $y m a B$ (Fig. 1). This fusion was inserted into the amyE locus.

A $538 \mathrm{bp}$ fragment corresponding to the $3^{\prime}$ end of $y m a B$, with artificial EcoRI and BamHI sites, was produced by PCR using the primers $5^{\prime}$ GGAATTCAGTGAAGATAGCAGAGTAGCA $3^{\prime}$ and $5^{\prime}$ GCCCTAGGTTATTCAAGAATATCAACAACA $3^{\prime}$ [the residues corresponding respectively to nt 4533-4554 and 5049-5070 of Z68500 (GenBank accession no.) are underlined]. Following purification and restriction, the fragment was cloned into pJM783 (Perego, 1993).

The plasmid obtained, pM783/538 EB, was used to transform competent cells of strains PB168 or PB1831, selecting for $\mathrm{Cm}^{\mathrm{R}}$. The integration by single crossover in the region of homology, provided by the insert, placed the $\operatorname{lac} Z$ reporter gene downstream of the whole operon. The construction was verified by Southern hybridization.

A 487 bp fragment with artificial EcoRI and BamHI ends, corresponding to the intercistronic region between $n r d F$ and $y m a B$, was synthesized by PCR using the primers $5^{\prime}$ GGAATTCCTACAGCGGTTTCTATTAT $3^{\prime}$ and 5' CGGGATCCTTATATCTGCTCTTTTTCAT $3^{\prime}$ corresponding respectively to nt 3914-3932 and 4400-4381, and cloned in the vector pJM115. The derived plasmid, named pJM115/487 EB was linearized and used to transform competent cells of strain PB168 selecting for $\mathrm{Km}^{\mathrm{R}}$. Double crossover events caused by the insertion of the $n r d F-l a c Z$ fusion at the amyE locus gave an Amy ${ }^{-}$phenotype.

The other plasmids used for sequencing and insertional gene inactivation of the three main coding sequences of the $n r d$ operon were constructed by cloning suitable restriction fragments in the integrative vector pJM103 and are partially listed in Table 2.

Transformation. E. coli transformation was performed following standard protocols (Hanahan, 1985). B. subtilis competent cells (Hoch et al., 1967) were transformed using 0.5-1 $\mathrm{gg}$ plasmid DNA or $0 \cdot 02-0 \cdot 1 \mu \mathrm{g}$ chromosomal DNA (Albertini \& Galizzi, 1985).

Sequencing. Sequencing was performed on plasmid subclones in pJM103 (Table 2) obtained from the EcoRI-Sall fragment of $\lambda \mathrm{CH} 4 \mathrm{G} 621$ as indicated in Fig. 1. The overlapping HindIII fragment was amplified by reverse PCR, recovering a fragment of $1.87 \mathrm{~kb}$ (dashed in Fig. 1) from chromosomal DNA digested with HindIII, ligated and cut at the unique SacII site at nt 1782. Amplification was obtained with primers NRDA3, 5' CGCAC'TCATGAAGGAAGGAAAACGA 3', and NRDA4, 5' GAGCAATCGATATCTCCATGCAGCT 3 '. The plasmid subclones were sequenced with Sequenase (USB) or T7 (Pharmacia) sequencing kits. The reverse PCR product was sequenced with the Circumvent kit (Biolabs). In all cases the sequence was determined on both strands by primer walking using custom oligonucleotides synthesized with a Cyclon Plus Synthesizer (Milligene Biosearch). 
Table 1. B. subtilis strains used in this study

\begin{tabular}{|c|c|c|}
\hline Strain & Genotype* & Reference or source $\nmid$ \\
\hline PB168 & $\operatorname{trp} C-2$ & \\
\hline PB566 & $\operatorname{trp} C-2$ thy $A$ thy $B$ & J. Lederberg \\
\hline PB1679 & ilv $A-1$ metB-5 ts- $A 13$ & E3113 (D. Karamata) \\
\hline PB1783 & thy $A$ tby $B \operatorname{gln} A-100$ & JH 949 (J. Hoch) \\
\hline PB1831 & $\operatorname{trpC}-2$ phe-1 & JH642 (J. Hoch) \\
\hline PB1843 & $\operatorname{trp} C-2 \operatorname{rec} A-260 \operatorname{met} B-5 S P \beta(-)$ xin-1 erm & BGSC $1 \mathrm{~A} 746$ \\
\hline PB1848 & trpC-2 phe-1 nrd::pJM783/538 EB nrd-lacZ cat & \\
\hline PB1849 & $\operatorname{trpC}-2$ nrd::pJM783/538 EB nrd-lacZ cat & \\
\hline PB1850 & $\operatorname{trpC}-2$ thy $A$ thyB $n r d:: p J M 783 / 538$ EB nrd-lacZ cat & \\
\hline PB1851 & $\operatorname{trpC}-2$ phe-1 $\triangle$ comP-A nrd::pJM783/538 EB nrd-lacZ kan cat & \\
\hline PB1852 & $\operatorname{trp} C-2$ phe-1 rec $A-260$ nrd:: $p J M 783 / 538$ EB nrd-lac $Z$ erm cat & \\
\hline PB1854 & $\operatorname{trpC}-2$ thy $A$ thyB $\triangle \operatorname{com} P-A$ nrd::pJM783/538 EB nrd-lacZ kan cat & \\
\hline PB1855 & $\operatorname{trpC}-2$ thy $A$ thyB $\operatorname{rec} A-260$ nrd::pJM783/538 EB nrd-lacZ erm cat & \\
\hline PB1874 & $\operatorname{trpC-2}$ phe-1amyE::pJM115/487 EB nrd-lacZ kan & \\
\hline PB5091 & $\operatorname{trp} C-2 \Delta c o m P-A$ kan & QB4714 (T. Msadek) \\
\hline PB5137 & $\operatorname{trpC}-2$ phe-1 spo0 A-12 & JH646 (J. Hoch) \\
\hline
\end{tabular}

* cat, kean and erm are the determinants for resistance to chloramphenicol, kanamycin and erythromycin, respectively.

† BGSC, Bacillus Genetic Stock Center, Ohio, USA; J. Hoch, La Jolla, USA ; D. Karamata, Lausanne, Switzerland; J. Lederberg, New York, USA; T. Msadek, Paris, France.

(a)

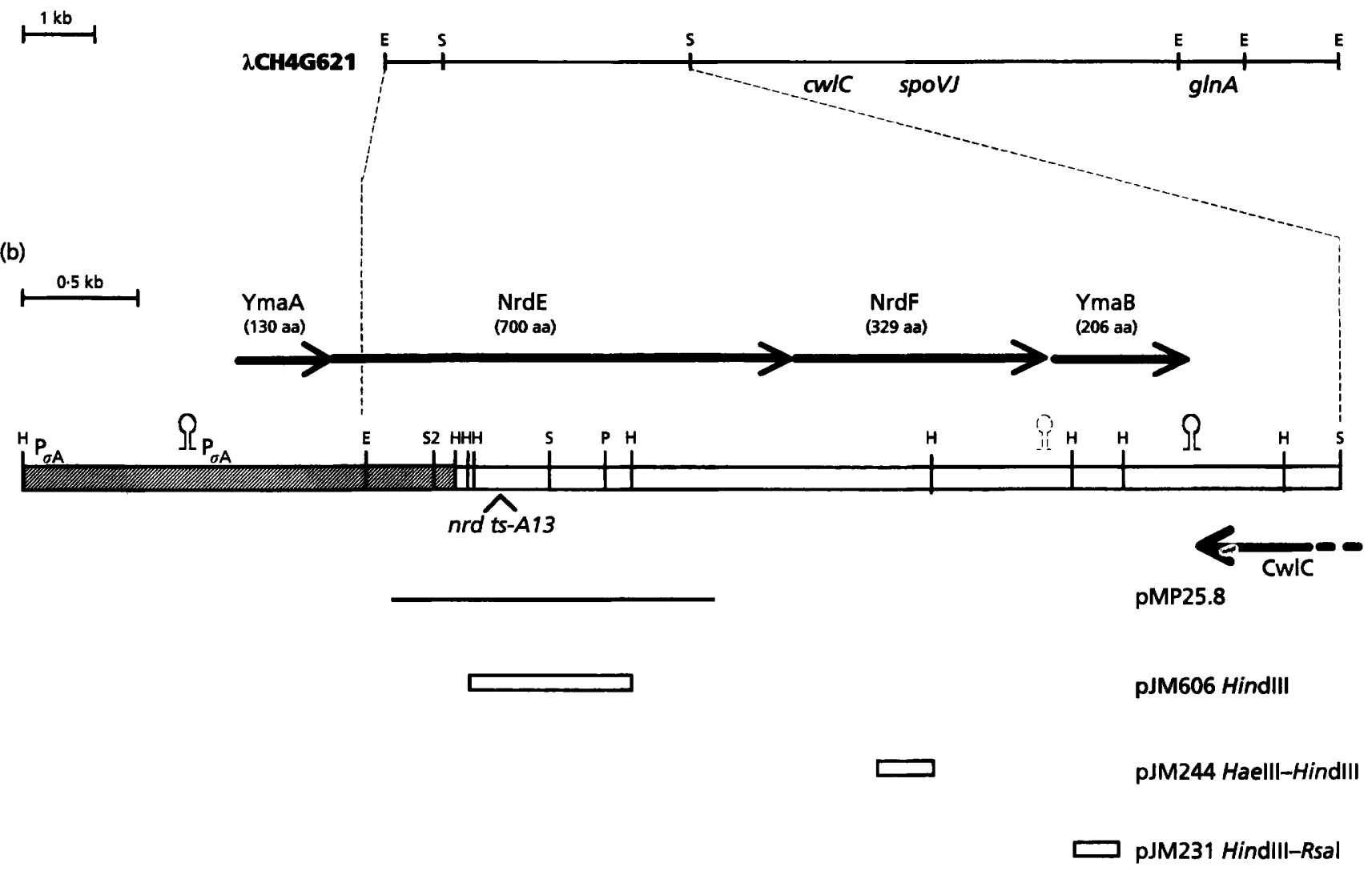

Fig. 1. Physical map and gene organization of the nrd locus of B. subtilis. (a) Clone $\lambda$ Ch4G621. (b) Map of the sequenced region. The hatched bar represents the sequence obtained by reverse PCR; arrows indicate the extent of the coding sequences; hairpins indicate putative terminator or attenuator structures; boxes indicate the localization of the fragments cloned in relevant plasmids. H, HindIII; E, EcoRI; S, Sall; P, Pstl; S2, Sacll. $\wedge$ indicates the position of the ts-A13 mutation. 
Table 2. Plasmids used in this study

\begin{tabular}{|c|c|}
\hline Plasmid & Description (source or reference) \\
\hline \multicolumn{2}{|l|}{ Vectors } \\
\hline pJH101 & Ap Tc Cm; integrative vector (Ferrari et al., 1983) \\
\hline pJM103 & Ap Cm; integrative vector (Perego, 1993) \\
\hline pJM783 & $\begin{array}{l}\text { Ap Cm; vector used to construct a lacZ transcriptional fusion } \\
\text { (Perego, 1993) }\end{array}$ \\
\hline pJM115 & $\begin{array}{l}\text { Ap } \mathrm{Km} \text {; vector used to construct } l a c Z \text { transcriptional fusion and } \\
\text { recombine into the chromosome at amyE, derivative of pDH32 } \\
\text { (Shimotsu \& Henner, 1986) }\end{array}$ \\
\hline \multicolumn{2}{|l|}{ Other plasmids } \\
\hline pMP25.8 & Ap Tc Cm; pJH101 derivative (Perego et al., 1987) \\
\hline pJM780 & Ap $\mathrm{Cm} ; 0.7 \mathrm{~kb}$ EcoRI-Sall fragment in pJM103 \\
\hline pJM3000 & Ap Cm; $3 \mathrm{~kb}$ Sall fragment in pJM103 \\
\hline pJM606 & $\begin{array}{l}\text { Ap Cm; } 0.6 \mathrm{~kb} \text { HindIII fragment subcloned from pJM3000 in } \\
\text { pJM103 }\end{array}$ \\
\hline pJM244 & $\begin{array}{l}\text { Ap Cm; } 0.2 \mathrm{~kb} \text { HindIII fragment subcloned from } \mathrm{pJM} 3000 \text { in } \\
\text { pJM103 }\end{array}$ \\
\hline pJM231 & $\begin{array}{l}\text { Ap Cm; } 0.2 \mathrm{~kb} H \text { indIII-RsaI fragment subcloned from pJM3000 in } \\
\text { pJM103 }\end{array}$ \\
\hline pJM783/538 EB & Ap Cm; $0.5 \mathrm{~kb}$ EcoRI-BamHI linked PCR fragment in pJM783 \\
\hline PJM115/487 EB & Ap $\mathrm{Cm} ; 0.4 \mathrm{~kb} E c o \mathrm{RI}-\mathrm{Bam} \mathrm{HI}$ linked PCR fragment in PJM115 \\
\hline
\end{tabular}

Sequencing of the ts-A13 mutation. The products obtained from two independent experiments of PCR amplification of chromosomal DNA of mutant strain $\mathrm{PB} 1679$ using the primers

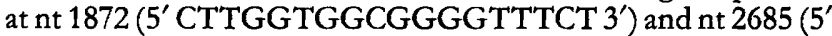
AGCACCGAGGCCGATTGA $3^{\prime}$ ) were digested with HindIII and cloned in pJM103 to be sequenced on both strands. We considered as mutations only the base substitutions verified on clones obtained from both the independent PCR reactions.

$\boldsymbol{\beta}$-Galactosidase assay. $\beta$-Galactosidase activity in strains harbouring lac $Z$ transcriptional fusions was measured as described previously (Albertini \& Galizzi, 1990).

DNA manipulations. Plasmid and phage DNA preparations and Southern hybridization were performed according to standard protocols (Sambrook et al., 1989). B. subtilis chromosomal DNA was prepared by phenol extraction (Albertini \& Galizzi, 1985).

\section{RESULTS AND DISCUSSION}

\section{Cloning and sequencing of the nrd locus}

Plasmid clone pMP25.8 (Perego et al., 1987) was able to marker rescue the temperature-sensitive mutant $t s-A 13$ in transformation experiments and direct selection to ts ${ }^{+}$. None of the transformants was $\mathrm{Cm}^{\mathrm{R}}$. This observation indicated that integration by single crossover is probably lethal and that the insert of the plasmid was internal to the $n r d$ locus and not inclusive of the $5^{\prime}$ or $3^{\prime}$ boundaries. For this reason we started screening a $\lambda$ Charon $4 \mathrm{~A}$ bank (Ferrari et al., 1981) by plaque hybridization using labelled pMP25.8 as probe and identified one positive clone, $\lambda$ G621, with an insert of about $13 \mathrm{~kb}$ (Fig. 1). The restriction map of the clone was similar to that of clone $24 \mathrm{~A}-2 \mathrm{~T}-4$ isolated from the same bank and bearing the sequence corresponding to the $t s-A 13$ and $\operatorname{gn} \mathrm{R} A$ loci (Fisher et al., 1984). DNA from phage $\lambda \mathrm{G} 621$ did in fact transform $g \ln A-100$ to prototrophy, supporting the idea that the two clones are identical.

We subcloned the $780 \mathrm{bp} E c o \mathrm{RI}-S_{a l}$ f fragment of pJM780 and the $3283 \mathrm{bp}$ SalI fragment of pJM3000 in pJM103 (Perego, 1993) and sequenced by primer walking. Analysis of the sequence revealed the existence at the $5^{\prime}$ end of an incomplete ORF showing similarity to the major subunit of class I RRs. To extend the cloning in the $5^{\prime}$ direction, we tried, unsuccessfully, different strategies, i.e. chromosome walking with various integrative plasmids and screening of different $B$. subtilis $\lambda$ or plasmid libraries. The sequence was obtained by reverse PCR and direct sequencing of the PCR product (see Methods).

\section{Organization of the nrd locus}

Analysis of the sequence comprising the $n r d$ locus and the surrounding region, performed using the BLAST (Altschul et al., 1990) and FASTA (Pearson, 1990) collections of programs, revealed the following features. The first 865 bp are characterized by short, less than 279 bp ORFs on both strands, whose deduced products did not show any similarity to known proteins. Nevertheless, we found the consensus for a putative $\sigma \mathrm{A}$ promoter at nt $51-80$ and a hairpin-loop structure $\left(\Delta G-114 \mathrm{~kJ} \mathrm{~mol}^{-1}\right)$ at $\mathrm{nt}$ 745-776, suggesting that the sequence corresponds to a transcription unit without coding capacities.

A second consensus for a putative $\sigma \mathrm{A}$ promoter could be recognized between nt 865 and 891, followed at nt 921-926 by a putative ribosome binding site just upstream of the GTG start codon of an ORF, named yma $A$ (Fig. 1). The predicted polypeptide of 130 aa (expected $M_{\mathrm{r}} 14600$ ) showed significant similarity to the deduced product of 
short ORFs of unknown function just upstream of the nrdEF operons of $S$. typbimurium (ORFB) and E. coli (ORFC) (Jordan et al., 1996). A similar polypeptide was also predicted in Lactococcus lactis (GenBank accession no. X92690) and in Mycoplasma genitalium (predicted coding region MG230, Fraser et al., 1995). In all cases the ORFs seem to be part of an $n r d E F$ operon.

A ribosome binding site consensus at nt 1276-1283 precedes an ORF encoding a polypeptide of $700 \mathrm{aa}$, with a predicted $M_{\mathrm{r}}$ of 80700 , showing high similarity (identity score $44-53 \%$ ) to the second group of enterobacterial class I RRs described by Jordan et al. (1994a, b). The same type of RR was isolated from Mycobacterium tuberculosis (Yang et al., 1994) and deduced to be present in Myc. genitalium (Fraser et al., 1995). The high similarity is evident in the multiple alignment shown in Fig. 2, and extends beyond the conserved three cysteines of the essential thiol, characterizing all the large RR subunits of class I. As in the case of the NrdE subunits of Enterobacteriaceae, the similarity with the prokaryotic NrdA subunit is low (22\% identity), even lower than the similarity observed with the eukaryotic RR major subunits $(25 \%$ identity).

A ribosome binding site consensus at nt 3397-3401 precedes a sequence (nt 3411-4400) potentially encoding a polypeptide of $329 \mathrm{aa}$, with an expected $M_{\mathrm{r}}$ of 38400 , with high similarity to the second group of class I minor subunits of RR, namely NrdF, found in Enterobacteriaceae (Jordan et al., 1994a, b) and Myc. genitalium (Fraser et al., 1995). Fig. 2 shows the alignment between the NrdF polypeptides sharing identity scores between 39 and $54 \%$. In this case as well, the similarity extends beyond the conservation of residues involved in defined functions such as the major subunit binding surface, the environment of the tyrosyl residue, the hydrogen bonding network, the iron ligands and the four $\alpha$-helix domains surrounding them. The similarity with other class I minor subunits is lower, ranging from $23 \%$ identity with the eukaryotic ones and $21 \%$ with $\mathrm{NrdB}$ of $E$. coli or bacteriophage $\mathrm{T} 4$.

No terminator site or recognizable promoter was identified between yma $A$ and $n r d E$, or between $n r d E$ and $n r d F$. In addition, the general organization of the coding sequences is very similar to that of the characterized $n r d E F$ operon of $S$. typhimurium and E. coli (Jordan et al., 1996). We thus propose that the three ORFs belong to the same operon.

It should be pointed out that the B. subtilis nrd operon, even though highly similar to the enterobacterial $n r d E F$ operon, lacks a gene encoding a polypeptide similar to glutaredoxin, the proposed electron donor for the NrdEF enzyme (Jordan et al. 1996). Such an ORF is not present even in the proximity of the $n r d$ locus.

The stop codon of the putative $\mathrm{NrdF}$ coding region is part of the loop of a stem-loop structure with a stability of $-114 \mathrm{~kJ} \mathrm{~mol}^{-1}$, followed by a putative ribosome binding sequence (nt 4432-4439) which precedes an ATG codon. The following ORF (nt 4450-5070), named ymaB, could encode a polypeptide of 206 aa, with a predicted $M_{\mathbf{r}}$ of 23400 . It should be noted that a partial consensus to a $\sigma \mathrm{A}$ promoter, which could drive the transcription of $y \mathrm{maB}$, is present between nt 4345 and 4372.

The hypothetical product $\mathrm{YmaB}$ is devoid of similarity to known proteins or to hypothetical products present in data banks. The ORF is followed by a hairpin-loop structure (Fig. 1) that could act as a strong ( $\Delta G-169 \cdot 9 \mathrm{~kJ}$ $\mathrm{mol}^{-1}$ ) terminator for the $n r d$ operon and for the transcription unit on the complementary strand (ORF from nt 5559 to 5134), that corresponds to the $3^{\prime}$ end of the $c w l C$ gene described by Kuroda et al. (1993).

\section{Inactivation of the three main coding sequences}

The three subclones pJM606, pJM244 and pJM231 (described in Table 2) were used as insertional vectors to specifically interrupt, by insertion of the plasmid, the three major ORFs, i.e. $n r d E, n r d F$ and $y m a B$, respectively. In all instances the restriction fragments used to target the insertion of the plasmid in the chromosome forced the recombination event in an internal region of the gene as indicated in Fig. 1.

We used these plasmids to transform competent cells of $B$. subtilis to $\mathrm{Cm}^{\mathrm{R}}$ and we never obtained transformants. This result is similar to that obtained with plasmid pMP25.8. Since we had no difficulty in obtaining transformants by a single crossover event using plasmid pJM3000, bearing the $C$ terminus of $n r d E$ and the entire coding regions of $n r d F$ and $y m a B$, we deduced that the interruption of the operon was probably lethal and that at least the further downstream ORF ymaB encodes an essential function.

\section{Mapping and sequencing of the ts-A13 mutation}

Bazill \& Karamata (1972) analysed the conditional lethal mutant, $t s-A 13$, impaired in ribonucleotide reductase activity. It is the only conditional lethal mutant reported for this function in B. subtilis, suggesting that the mutation impairs the functionally relevant class I enzyme of this organism.

Perego et al. (1987) isolated pMP25.8, an integrative plasmid able to marker rescue to $\mathrm{ts}^{+}$the temperaturesensitive mutant $t s-A 13$. To define more precisely the region of the mutation, we subcloned a number of DNA fragments and tested them in marker rescue experiments.

Among the subclones, plasmid pJM606, unable to transform cells to $\mathrm{Cm}^{\mathbf{R}}$, was able to give ts ${ }^{+}$transformants when used to transform strain PB1679. The same HindIII fragment was obtained by PCR amplification from chromosomal DNA of the mutant strain PB1679 and was sequenced. We found three mutations: two in close proximity (GC $\rightarrow$ AT transition at nt 2292; AT $\rightarrow$ GC transition at nt 2295) were silent substitutions in the third position of the codons for Lys333 and Glu334 of NrdE and the third mutation was a CG $\rightarrow$ TA transition, changing His 255 of NrdE to Tyr. This histidine residue is conserved in all class I major subunits of RR so far examined, and corresponds to the last residue (His308) of 
(a)

NrdEB.s.

NrdES.t.

NrdEM.g.

NrdEM.t

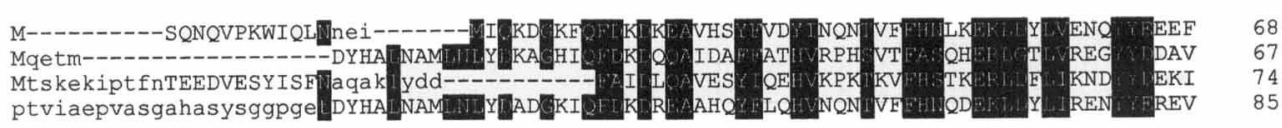

NrdEB.s.

NrdES.t.

NrdEM. $g$.

NrdEM.t

NrdEB.s.

NrdES.t.

NrdEM. $g$.

NrdEM.t

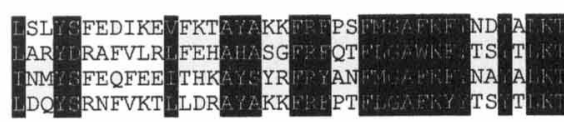

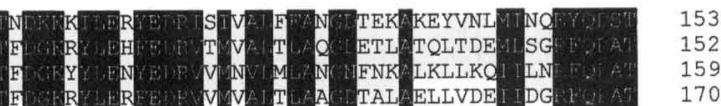

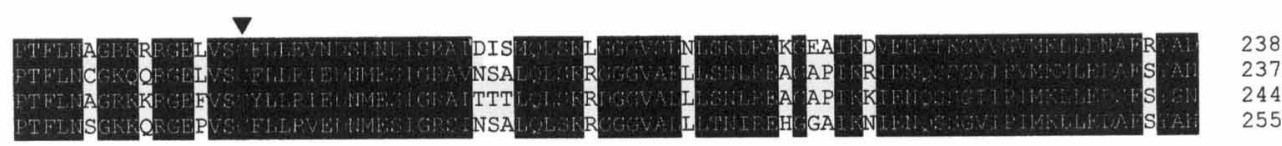

NrdeB.s.

NrdES.t.

NrdEM.g.

NrdEM.t

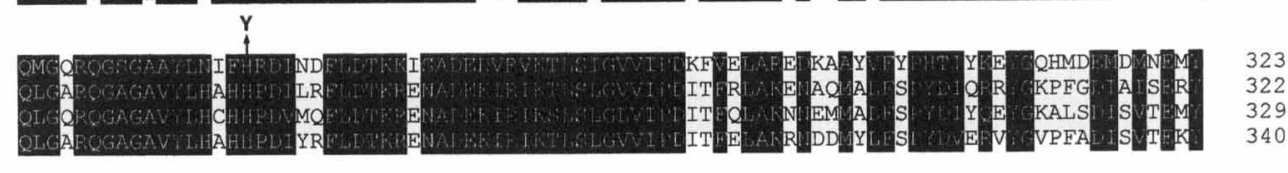

NrdEB.s.

NrdES.t.

NrdEM. $g$.

NrdEM.t

NrdEB.s.

NrdES.t.

NrdEM. $g$.

NrdEM.t

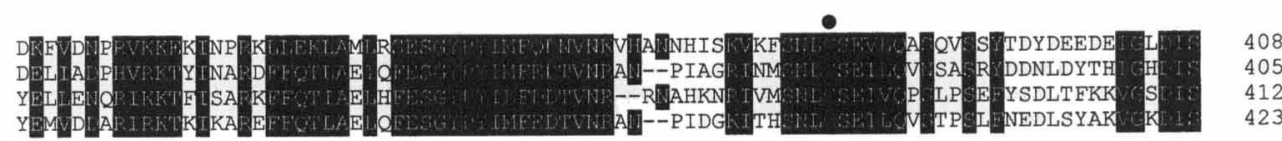

$\nabla$

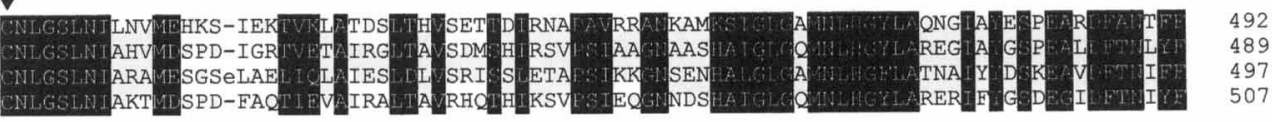

NrdEB.s .

NrdES.t.

NrdEM. $g$.

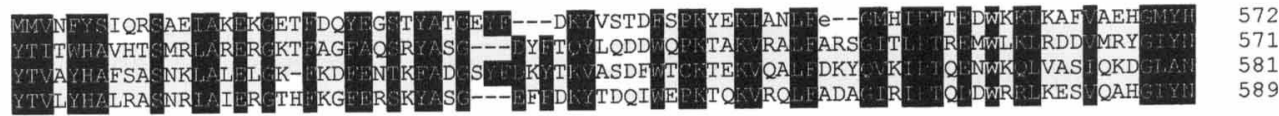

NrdEB.s.

NrdES.t.

NrdEM. $g$.

NrdFM.t

NrdEB.s.

NrdES.t.

NrdEM. $g$.

NrdEM. $t$

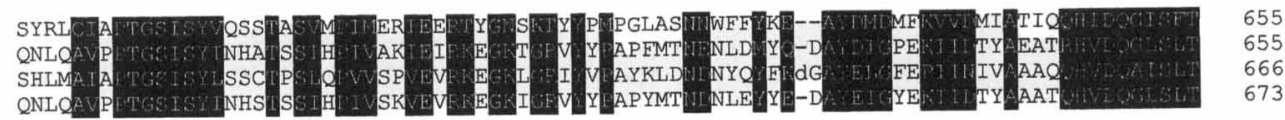

(b)

NrdFB.s. NrdFS.t. NrdFM.g. NrdFE, c.

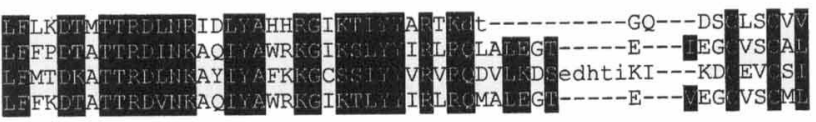

NrdFB.s. NrdFs. $t$. NrdFM.g. NrdFE.c.

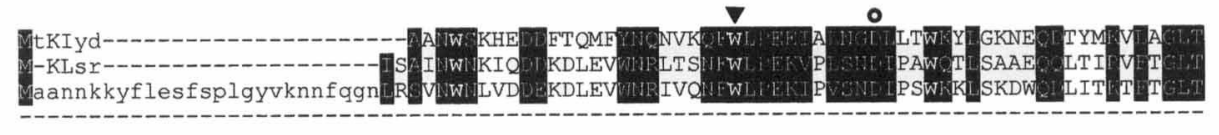

NrdFB.s. NrdFS.t. NrdFM.g. NrdFE.c.

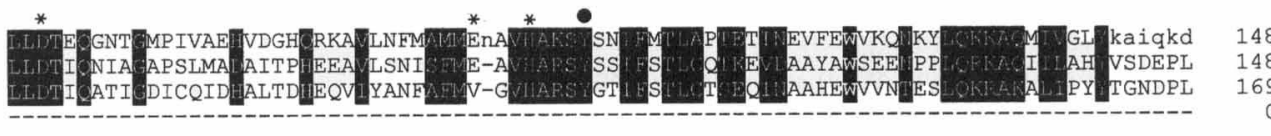

NrdFB.s . NrdFS.t. NrdFM. $g$. NrdFE.c.

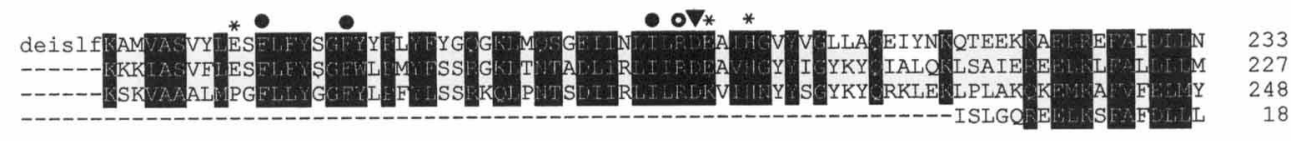

NrdFB.s .

NrdFS.t.

NrdFM. $g$.

NrdFE. C.
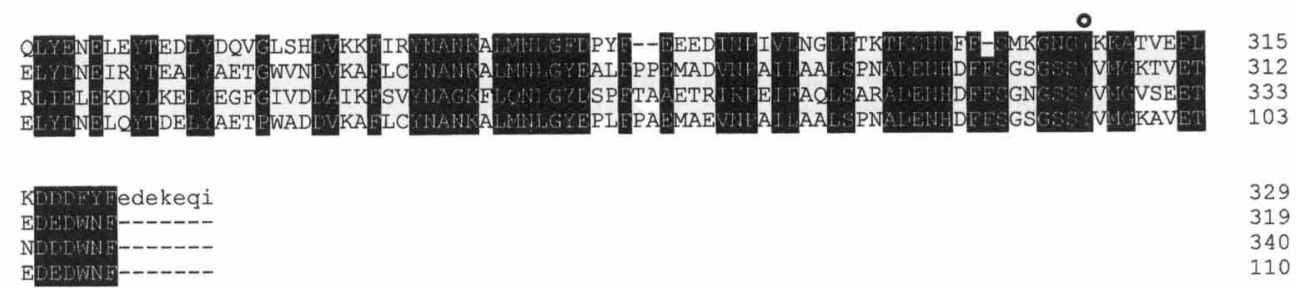

Fig. 2. For legend see facing page. 

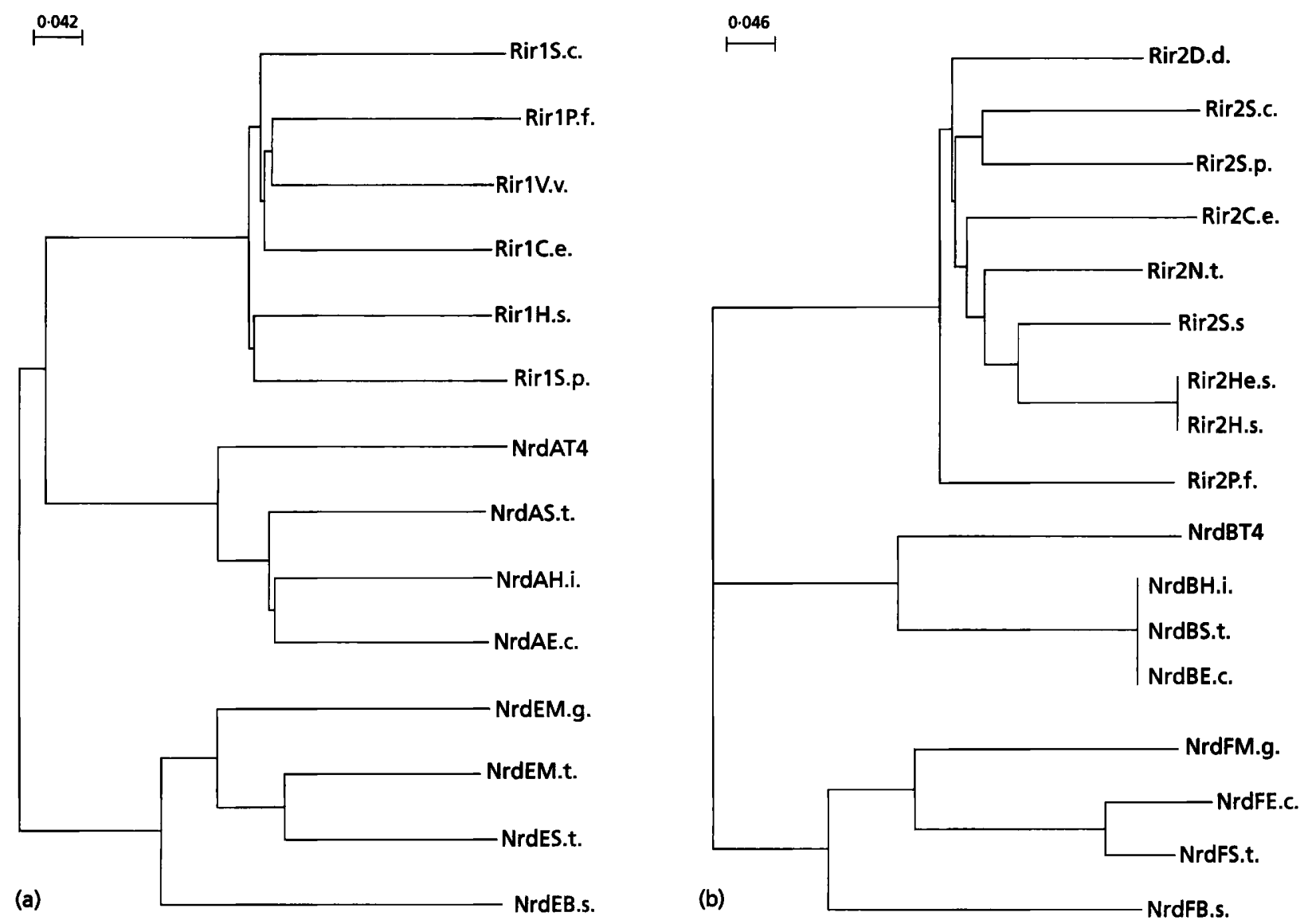

Fig. 3. Phylogenetic analysis of the class I major subunits (a) and minor subunits (b) of RR graphically displayed using the NJPLOT software of M. Gouy (University of Lyon, France). The scale bars indicate the distances as calculated from the multiple alignment (Thompson et al., 1994). Species abbreviations and protein or DNA sequence accession numbers used for (a) are: NrdEB.s., B. subtilis (Z68500); NrdES.t., S. typhimurium (Q08698); NrdEM.t., Myco. tuberculosis (L34407); NrdEM.g., Myc. genitalium (U39701); NrdAE.C., E. coli (P00452); NrdAH.i., H. influenzae (P43754); NrdAS.t., S. typhimurium (P37426); NrdAT4, bacteriophage T4 (P32282); Rir1S.p., Schizosaccharomyces pombe (Z67998); Rir1H.S., Homo sapiens (P23921); Rir1C.e., Caenorhabditis elegans (Q036304); Rir1V.v., Vaccinia virus (P20503); Rir1P.f., Plasmodium falciparum (A49412); Rir1S.c., Saccharomyces cerevisiae (P21524). For (b): NrdFB.s., B. subtilis (Z68500); NrdFS.t., S. typhimurium (P17424); NrdFE.C., E. coli (P37146); NrdFM.g., Myc. genitalium (P47471); NrdBE.C., E. coli (P00453); NrdBS.t., S. typhimurium (P37427); NrdBH.i., H. influenzae (P43755); NrdBT4, bacteriophage T4 (P11156); Rir2P.f., P. falciparum (B49412); Rir2H.s., H. sapiens (P31359); Rir2He.s., Herpes simplex virus (P28847); Rir2S.s., Spisula solidissima (P07201); Rir2N.t., Nicotiana tabacum (X92443); Rir2C.e., C. elegans (P42170); Rir2S.p., Schiz. pombe (P36603); Rir25.C., Sacch. cerevisiae (P09938); Rir2D.d., Dictyostelium discoideum (P42521).

the $\beta C$ sheet of the $\alpha / \beta$ barrel domain described in the three-dimensional structure of the NrdA subunit (Uhlin \& Eklund, 1994). We infer that this mutation is the one responsible for the temperature-sensitive phenotype of the $t s-A 13$ mutant allele.

The identification of three mutations, two neutral and one that is presumably responsible for the conditional lethal phenotype, in a short stretch of DNA sequence can be explained by the fact that the mutant $t s-A 13$ was isolated after NTG treatment, a mutagen which acts on the DNA replicative fork and is known for inducing multiple mutations (Karamata \& Gross, 1970).

The localization in $n r d E$ of the mutation that impairs the activity of the class I RR (Bazill \& Karamata, 1972) and the evidence that the $n r d E F$ operon cannot be inactivated led us to infer that this operon exerts a role essential for the biosynthesis of deoxyribonucleotides. It seems safe to conclude that the $\mathrm{NrdER}_{1} / \mathrm{NrdFR}_{2}$ enzyme plays the

Fig. 2. Multiple alignments (a) of NrdE polypeptides, major subunits of RR, and (b) of NrdF polypeptides, minor subunits of RR, found in B. subtilis (B.s.), E. coli (E.c.), S. typhimurium (S.t.), Myc. genitalium (M.g.) and Myco. tuberculosis (M.t.). GenBank accession numbers are given in the legend to Fig. 3. (a) In the NrdE alignment, indicates the Cys residues proposed for the $3^{\prime}$ hydrogen abstraction of the substrate and $\boldsymbol{\nabla}$ indicates the two Cys residues of the active site. (b) In the NrdF alignment, the functionally relevant conserved residues are indicated by the following symbols: $\nabla$, hydrogen bonding network sites; $O$, residues of the tyrosyl radical environment; $O$, residues of the major subunit binding surface; *, iron ligand residues. 
Table 3. Expression of the nrd operon

The indicated values represent the mean of at least two experiments and were the highest obtained from a series of samples assayed at various times during growth. ND, not determined.

\begin{tabular}{|c|c|c|c|c|}
\hline \multirow[t]{2}{*}{ Strain } & \multicolumn{4}{|c|}{$\begin{array}{c}\left.\beta \text {-Galactosidase activity [U (mg protein })^{-1}\right]^{*} \\
(n r d:: p J M 783 / 538 \text { EB nrd-lacZ fusion) }\end{array}$} \\
\hline & $\begin{array}{l}\text { SM } \\
\text { medium }\end{array}$ & $\begin{array}{c}\text { SM } \\
\text { medium } \\
(-)\end{array}$ & $\begin{array}{l}\text { TM } \\
\text { medium }\end{array}$ & $\begin{array}{c}\text { TM } \\
\text { medium } \\
(-)\end{array}$ \\
\hline PB1848 wild-type & 13 & 14 & 8 & 9 \\
\hline PB1849 wild-type & 12 & ND & $14 \cdot 2$ & ND \\
\hline PB1850 Thy $^{-}$ & $28 \cdot 5$ & 35 & $23 \cdot 1$ & $50 \cdot 6$ \\
\hline PB1851 Com ${ }^{-}$ & $11 \cdot 5$ & ND & $8 \cdot 5$ & ND \\
\hline PB1852 Rec ${ }^{-}$ & 10 & ND & 8 & ND \\
\hline PB1854 Com ${ }^{-}$Thy $^{-}$ & 22 & $33 \cdot 5$ & $28 \cdot 5$ & 52 \\
\hline PB1855 Rec ${ }^{-}$Thy $^{-}$ & 21 & $28 \cdot 2$ & $21 \cdot 5$ & $16 \cdot 5$ \\
\hline
\end{tabular}

* SM, Schaeffer Medium; TM, competence minimal medium (Anagnostopoulos \& Spizizen, 1961). Both media were supplemented with $50 \mu \mathrm{g}$ thymidine $\mathrm{ml}^{-1}$. (-) indicates thymidine deprivation.

same role in $B$. subtilis that the $\mathrm{NrdAR}_{1} / \mathrm{NrdBR}_{2}$ enzyme plays in Enterobacteriaceae. In E. coli and in S. typhimurium, the $n r d E F$ operon, even if expressed, is not essential, and in standard conditions is unable to replace the absence of $\mathrm{NrdAR}_{1} / \mathrm{NrdBR}_{2}$ activity (Jordan et al., 1996). Although at present we cannot rule out the hypothesis that an $n r d A B$-type operon is present in the $B$. subtilis genome, it appears that $B$. subtilis made a functional choice concerning the RR enzyme different from that made by the Enterobacteriaceae. The same choice was made by $M y c$. genitalium: in the whole genome only one locus is devoted to deoxyribonucleotide biosynthesis and it appears to be organized in an operon with three ORFs, the $n r d F$ homologue, the homologue of $B$. subtilis ymaA and the $n r d E$ homologue. With the exception of the relative order of genes, the genetic tools present in Myc. genitalium are the same as found in B. subtilis. Haemophilus influenzae, the other bacterium for which the entire genome has been sequenced (Fleischmann et al., 1995), made the opposite choice: only an $\operatorname{nrd} A B$ operon is present.

Prokaryotes evolved different strategies for deoxyribonucleotide production (Reichard, 1993), namely class I and class II aerobic and class III anaerobic enzymes. The three classes are not related at the level of primary structure. In addition, if we examine the variety of aerobic $\mathrm{Fe}$ (III)-tyrosyl radical-based class I enzymes, a category comprising the eukaryotic enzymes, we observe a wide diversification at the level of primary structure. Fig. 3 represents the phylogenetic analysis of $R R$ major and minor subunits: the $\mathrm{NrdER}_{1} / \mathrm{NrdFR}_{2} \mathrm{RR}$ diverged from $\mathrm{NrdAR}_{1} / \mathrm{NrdBR}_{2}$ enzymes at least as much as both diverged from the eukaryotic enzymes. In the case of the major subunits, the NrdA-type polypeptides are more similar to the eukaryotic counterpart than to the $\mathrm{NrdE}$ prokaryotic polypeptide.

New questions arise from these observations. Why did
Enterobacteriaceae and $H$. influenqae make a functional choice (in the case of Enterobacteriaceae, maintaining both the genetic equipment and the production at low levels of the $\mathrm{NrdER}_{\mathbf{1}} / \mathrm{NrdFR}_{\mathbf{2}}$ enzyme) different from $B$. subtilis and $M y c$. genitalium? Is it possible that an ancestor of Enterobacteriaceae acquired the $n r d A B$ genes from a bacteriophage, such as T4, which has an RR highly similar to the $\mathrm{NrdAR}_{1} / \mathrm{NrdBR}_{2}$ enzyme, and the newly acquired enzyme has been raised to a higher functional role in the course of evolution? Is the choice of the Enterobacteriaceae in some way related to the presence of the anaerobic $n r d D$ encoded class III enzyme, proposed as the closest relative of the common ancestor of all RRs (Reichard, 1993)? In more general terms, why do we find class II enzymes in Eubacteria (e.g. Lactobacillus leichmanii; Booker \& Stubbe, 1993) and so many types of class I enzymes?

The completion of the sequencing projects of the entire genome of $B$. subtilis and other bacteria will answer some of these questions. At present the finding that the $n r d$ genes of $M y c$. genitalium are phylogenetically closer to the $n r d E F$ genes of $B$. subtilis than to the $n r d A B$ genes of Enterobacteriaceae confirms other observations indicating an evolutionary relationship between Mycoplasma and Gram-positive bacteria (Fraser et al., 1995).

\section{Expression of the $n$ rd operon}

The genetic analysis indicated that the coding sequence $y m a B$ was essential. In contrast, inspection of the sequence between $n r d F$ and $y m a B$ revealed the presence of a stemloop structure, which could act as an attenuator or terminator of transcription, and the presence of a putative $\sigma \mathrm{A}$ promoter. Therefore, we tested for the possible activity of the $n r d F, y m a B$ intercistronic region, by cloning it upstream of a promoterless $l a c Z$ gene in the integrative plasmid pJM115. Strain PB1874, carrying the fusion in the amy $E$ locus, did not synthesize $\beta$-galactosidase, 


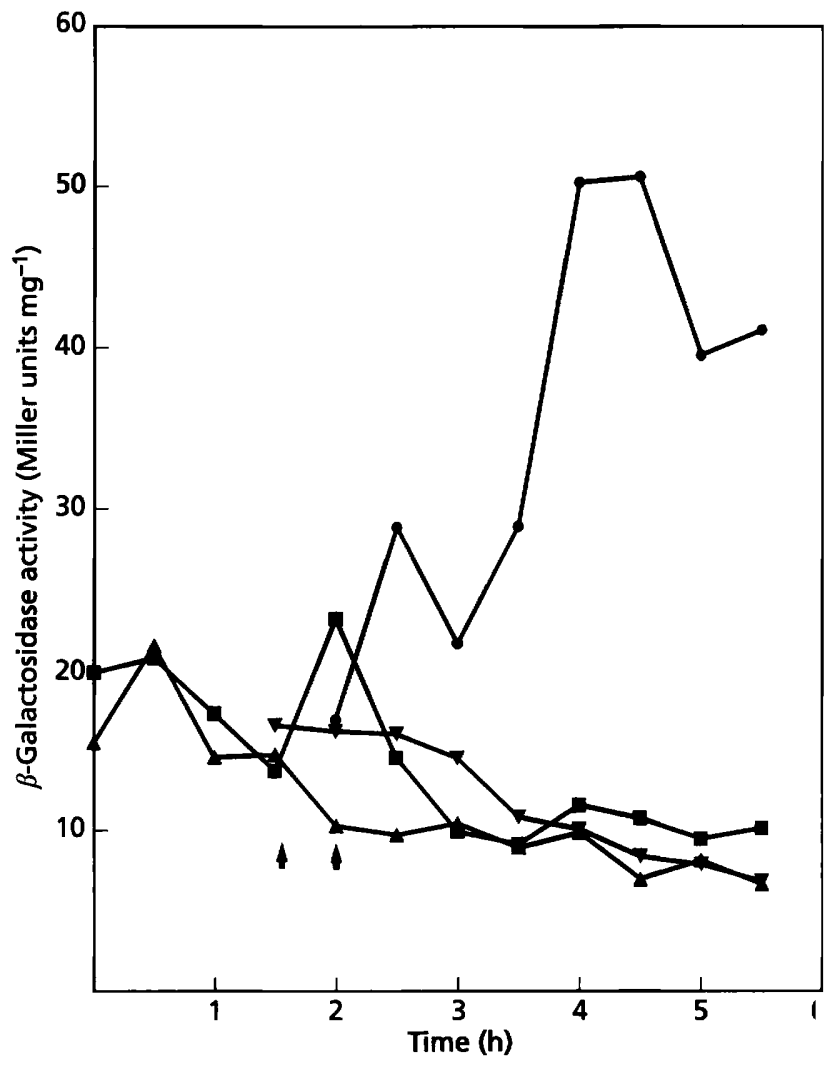

Fig. 4. $\beta$-Galactosidase assays of the nrd-lacz fusion monitoring the induction of operon transcription by thymidine starvation. Half of the cultures in TM medium supplemented with thymidine $\left(50 \mu \mathrm{g} \mathrm{ml}^{-1}\right)$ were collected at the indicated times (arrows), washed by centrifugation and resuspended in the same medium without thymidine. $\square$, wild-type strain; 0 , wildtype strain starved of thymidine; $\Delta, \operatorname{Rec}^{-}$strain; $\nabla, \operatorname{Rec}^{-}$strain starved of thymidine.

suggesting the absence of a functional promoter in the intercistronic sequence (data not shown).

We propose that $y m a B$ is co-transcribed with $y m a A, n r d E$ and $n r d F$, and thus is part of the $n r d$ operon.

To study the level of expression and to perform a preliminary analysis of the transcriptional control of the $n r d$ operon, we used a lac $Z$ transcriptional fusion, inserted into the chromosome downstream of $y m a B$. The fusion by means of plasmid pJM783/538 EB gave the results summarized in Table 3 and represented in Fig. 4. The level of transcription was low, but significant in rich and minimal media, and the presence of the mutations $\Delta c o m P-A$ and $\operatorname{rec} A-260$ did not change the basal level of transcription significantly.

As in the case of the $n r d A B$ operon of E. coli (Filpula \& Fuchs, 1978), the transcription of RR genes increased as a consequence of a block of DNA synthesis obtained by thymidine starvation in the thymidine-requiring strain PB1850 (Fig. 4). Since this effect was higher in TM medium, a medium for the induction of competence in $B$. subtilis (Anagnostopoulos \& Spizizen, 1961), we tested if it was part of the competence response, and thus positively controlled by the response regulators ComP-A (Dubnau, 1993), or part of the RecA-controlled responses (Love \& Yasbin, 1984).

In the $\Delta$ comP- $A$ mutant strain PB1854, the peak of induction by thymidine starvation was comparable to that reached by the parental strain (Table 3 ). In contrast, the $\operatorname{rec} A$ mutant PB1855 was severely affected in its ability to induce the operon after thymidine starvation (Fig. 4).

We can explain these results by the hypothesis that in $B$. subtilis, as in E. coli for $\operatorname{nrd} A B$, the $n r d E F$ operon is under the control of cell cycle and as a consequence under the influence of the SOS regulator RecA. In B. subtilis, RecA synthesis is induced both by thymidine starvation (Love \& Yasbin, 1984) and by the attainment of the competence phase (Yasbin et al., 1993). Since in the $\triangle$ comP- $A$ mutant, thymidine starvation was still effective in inducing transcription of the $n r d$ operon, we conclude that the increased level of expression of the operon is not due to the attainment of the competent state. The $\mathrm{nrd}$ induction can be tentatively classified as a Type I SOS phenomenon following the indication of Yasbin (1993).

These preliminary observations reinforce the suggestion that this is the functionally relevant operon in the synthesis of deoxyribonucleotides and is subject to fine control of expression to modulate their synthesis.

\section{ACKNOWLEDGEMENTS}

This work was supported in part by the European Commission under the Biotechnology programme (contract Bio2-CT930272) and by Consiglio Nazionale delle Ricerche (Grants 92.02183.CT 174 AND 93.02009.CT14).

\section{REFERENCES}

Albertini, A. M. \& Galizzi, A. (1985). Amplification of a chromosomal region in Bacillus subtilis. J Bacteriol 162, 1203-1211.

Albertini, A. M. \& Galizzi, A. (1990). The Bacillus subtilis outB gene is highly homologous to an Eschericbia coli ntr-like gene. $J$ Bacteriol 172, 5482-5485.

Altschul, S. F., Gish, W., Miller, W., Myers, E. W. \& Lipman, D. J. (1990). Basic Local Alignment Search Tool. J Mol Biol 215, 403-410.

Anagnostopoulos, C. \& Spizizen, J. (1961). Requirements for transformation of Bacillus subtilis. J Bacteriol 81, 741-746.

Augustin, L., Jacobson, B. A. \& Fuchs, J. A. (1994). Escherichia coli Fis and DnaA proteins bind specifically to $n r d$ promoter region and affect expression of an $n r d-$ lac fusion. $J$ Bacteriol 176, 378-387.

Bazill, G. W. \& Karamata, D. (1972). Temperature sensitive mutants in B. subtilis defective in deoxyribonucleotide synthesis. Mol Gen Genet 117, 19-29.

Booker, S. \& Stubbe, J. (1993). Cloning sequencing and expression of the adenosylcobalamin-dependent ribonucleotide reductase from Lactobacillus leicbmanii. Proc Natl Acad Sci US A 90, 8352-8356.

Dubnau, D. (1993). Genetic exchange and homologous recombination. In Bacillus subtilis and Other Gram-positive Bacteria: Biochemistry, Pbysiology and Molecular Genetics, pp. 555-578. Edited by A. L. Sonenshein, J. A. Hoch \& R. Losick. Washington, DC: American Society for Microbiology. 
Ferrari, E., Henner, D. J. \& Hoch, J. (1981). Isolation of Bacillus subtilis genes from a Charon 4A library. J Bacteriol 146, 430-432.

Ferrari, F. A., Nguyen, A., Lang, D. \& Hoch, J. A. (1983). Construction and properties of an integrable plasmid for Bacillus subtilis. J Bacteriol 154, 1513-1515.

Filpula, D. F. \& Fuchs, J. A. (1977). Regulation of ribonucleoside reductase synthesis in Escherichia coli: increased enzyme synthesis as a result of inhibition of deoxyribonucleic acid synthesis. $J$ Bacteriol 130, 107-113.

Filpula, D. F. \& Fuchs, J. A. (1978). Regulation of the synthesis of ribonucleotide diphosphate reductase in Escherichia coli: specific activity of the enzyme in relationship to perturbations of DNA replication. J Bacteriol 135, 429-435.

Fisher, S., Rosenkrantz, M. S. \& Sonenshein, A. L. (1984). Glutamine synthetase gene of Bacillus subtilis. Gene 32, 427-438.

Fleischmann, R. D. and others (1995). Whole-genome random sequencing and assembly of Haemopbilus influenzae Rd. Science 269, 496-512.

Fraser, C. M. and others (1995). The minimal gene complement of Mycoplasma genitalium. Science 270, 397-403.

Giannl, M. \& Galizzi, A. (1986). Isolation of genes preferentially expressed during Bacillus subtilis spore outgrowth. J Bacteriol 165, 123-132.

Gibert, I., Calero, S. \& Barbé, J. (1990). Measurement of in vivo expression of $n r d A$ and $n r d B$ genes of Escherichia coli by using lac $Z$ fusions. Mol Gen Genet 220, 400- 408.

Hanahan, D. (1985). Techniques for transformation of E. coli. In DNA Cloning: a Practical Approach, vol. I, pp. 109-132. Edited by D. M. Glover. Oxford: IRL Press.

Hanke, P. D. \& Fuchs, J. A. (1983). Characterization of the mRNA coding for ribonucleoside diphosphate reductase in Eschericbia coli. $J$ Bacteriol 154, 1040-1045.

Hoch, J. A., Barat, M. \& Anagnostopoulos, C. (1967). Transformation and transduction in recombination-defective mutants of Bacillus subtilis. J Bacteriol 93, 1925-1937.

Jordan, A., Gibert, I. \& Barbé, J. (1994a). Cloning and sequencing of the genes from $S$. typbimurium encoding a new bacterial ribonucleotide reductase. J Bacteriol 176, 3420-3427.

Jordan, A., Pontis, E., Atta, M., Krook, M., Gibert, I., Barbé, J. \& Reichard, P. (1994b). A second class I ribonucleotide reductase in Enterobacteriaceae: characterization of the Salmonella typhimurium enzyme. Proc Natl Acad Sci US A 91, 12892-12896.

Jordan, A., Argall, E., Gibert, I. \& Barbé, J. (1996). Promoter identification and expression analysis of Salmonella typhimurium and Escherichia coli nrdEF operons encoding one of two class I ribonucleotide reductase present in both bacteria. Mol Microbiol 19, $777-790$.

Karamata, D. \& Gross, J. D. (1970). Isolation and genetic analysis of temperature sensitive mutants of $B$. subtilis defective in DNA synthesis. Mol Gen Genet 108, 277-287.

Kuroda, A., Asami, Y. \& Sekiguchi, J. (1993). Molecular cloning of sporulation specific cell wall hydrolase gene of Bacillus subtilis. $J$ Bacteriol 175, 6260-6268.

Love, P. E. \& Yasbin, R. E. (1984). Genetic characterisation of the inducible SOS-like system of Bacillus subtilis. J Bacteriol 160, $910-920$.
Nordlund, P. \& Eklund, H. (1993). Structure and function of the Escherichia coli ribonucleotide reductase protein R2. J Mol Biol 232, 123-164.

Nordlund, P., Sjoberg, B.-M. \& Eklund, H. (1990). Three-dimensional structure of the free radical protein of ribonucleotide reductase. Nature 345, 593-598.

Pearson, W. R. (1990). Rapid and sensitive sequence comparison with FASTP and Fasta. Metbods Enzymol 183, 63-98.

Perego, M. (1993). Integrational vectors for genetic manipulations in Bacillus subtilis. In Bacillus subtilis and Other Gram-positive Bacteria: Biochemistry, Physiology and Molecular Genetics, pp. 615-624. Edited by A. L. Sonenshein, J. A. Hoch \& R. Losick. Washington, DC: American Society for Microbiology.

Perego, M., Ferrari, E., Bassi, M. T., Galizzi, A. \& Mazza, P. G. (1987). Molecular cloning of Bacillus subtilis genes involved in DNA metabolism. Mol Gen Genet 209, 8-14.

Reichard, P. (1993). From RNA to DNA, why so many ribonucleotide reductases? Science 260, 1773-1777.

Sambrook, J., Fritsch, E. F. \& Maniatis, T. (1989). Molecular Cloning: a Laboratory Manual. Cold Spring Harbor, NY: Cold Spring Harbor Laboratory.

Scotti, C., Piatti, M., Cuzzoni, A., Perani, P., Tognoni, A., Grandi, G., Galizzi, A. \& Albertini, A. M. (1993). A Bacillus subtilis large ORF coding for a polypeptide highly similar to polyketide synthases. Gene 130, 65-71.

Shimotsu, H. \& Henner, D. J. (1986). Construction of a single-copy integration vector and its use in analysis of regulation of the trp operon of Bacillus subtilis. Gene 43, 85-94.

Sun, L. \& Fuchs, J. A. (1992). Escberichia coli ribonucleotide reductase expression is cell cycle regulated $\mathrm{Mol} \mathrm{Biol} \mathrm{Cell} \mathrm{3,} \mathrm{1095-1105.}$

Sun, L., Jacobson, B. A., Dien, B. S., Srienc, F. \& Fuchs, J. A. (1994). Cell cycle regulation of the Escherichia coli nrd operon: requirement for a cis-acting upstream AT-rich sequence. $J$ Bacteriol 176, 2415-2416.

Sun, X., Harder, H., Krook, M., Jornvall, H., Sjorberg, B.-M. \& Reichard, P. (1993). A possible glycine radical in anaerobic ribonucleotide reductase from Escherichia coli: nucleotide sequence of the cloned $n r d D$ gene. Proc Natl Acad Sci US A 90, 577-581.

Thompson, J. D., Higgins, D. G. \& Gibson, T. J. (1994). CLustaL w : improving the sensitivity of progressive multiple sequence alignment through sequence weighting, position-specific gap penalties and weight matrix choice. Nucleic Acids Res 22, 4673-4680.

Uhlin, U. \& Eklund, H. (1994). Structure of ribonucleotide reductase protein R1. Nature 370, 533-539.

Yang, F., Guizhen, L. \& Rubin, H. (1994). Isolation of ribonucleotide reductase from Mycobacterium tuberculosis and cloning, expression and purification of the large subunit. $J$ Bacteriol 176, 6738-6743.

Yasbin, R. E., Cheo, D. \& Bol, D. (1993). DNA repair systems. In Bacillus subtilis and Other Gram-positive Bacteria: Biochemistry, Pbysiology and Molecular Genetics, pp. 529-537. Edited by A. L. Sonenshein, J. A. Hoch \& R. Losick. Washington, DC: American Society for Microbiology.

Received 18 April 1996; revised 2 July 1996; accepted 11 July 1996. 